\title{
Erratum to: Cisplatin Toxicity in Dorsal Root Ganglion Neurons Is Relieved by Meclizine via Diminution of Mitochondrial Compromise and Improved Clearance of DNA Damage
}

Murat F. Gorgun $^{1} \cdot$ Ming Zhuo $^{1}$ - Ella W. Englander ${ }^{1}$

Published online: 21 December 2016

(C) Springer Science+Business Media New York 2016

Erratum to: Mol Neurobiol.

DOI 10.1007/s12035-016-0273-9

The original version of this article unfortunately contained a production problem. At Fig. 3, the image under "cisplatin + meclizine and NF200" is missing on the online published paper both in the pdf and HTML version of this article.

The corrected Fig. 3 is hereby given below.

The original article was corrected.

The online version of the original article can be found at http:// dx.doi.org/10.1007/s12035-016-0273-9

Ella W. Englander elenglan@utmb.edu

1 Department of Surgery, University of Texas Medical Branch, 301 University Boulevard, Galveston, TX 77555, USA 

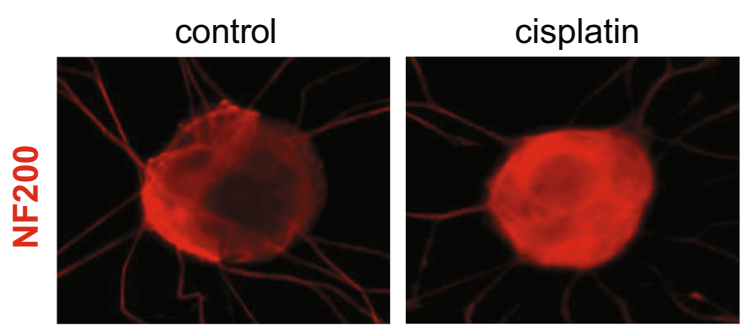

cisplatin + meclizine
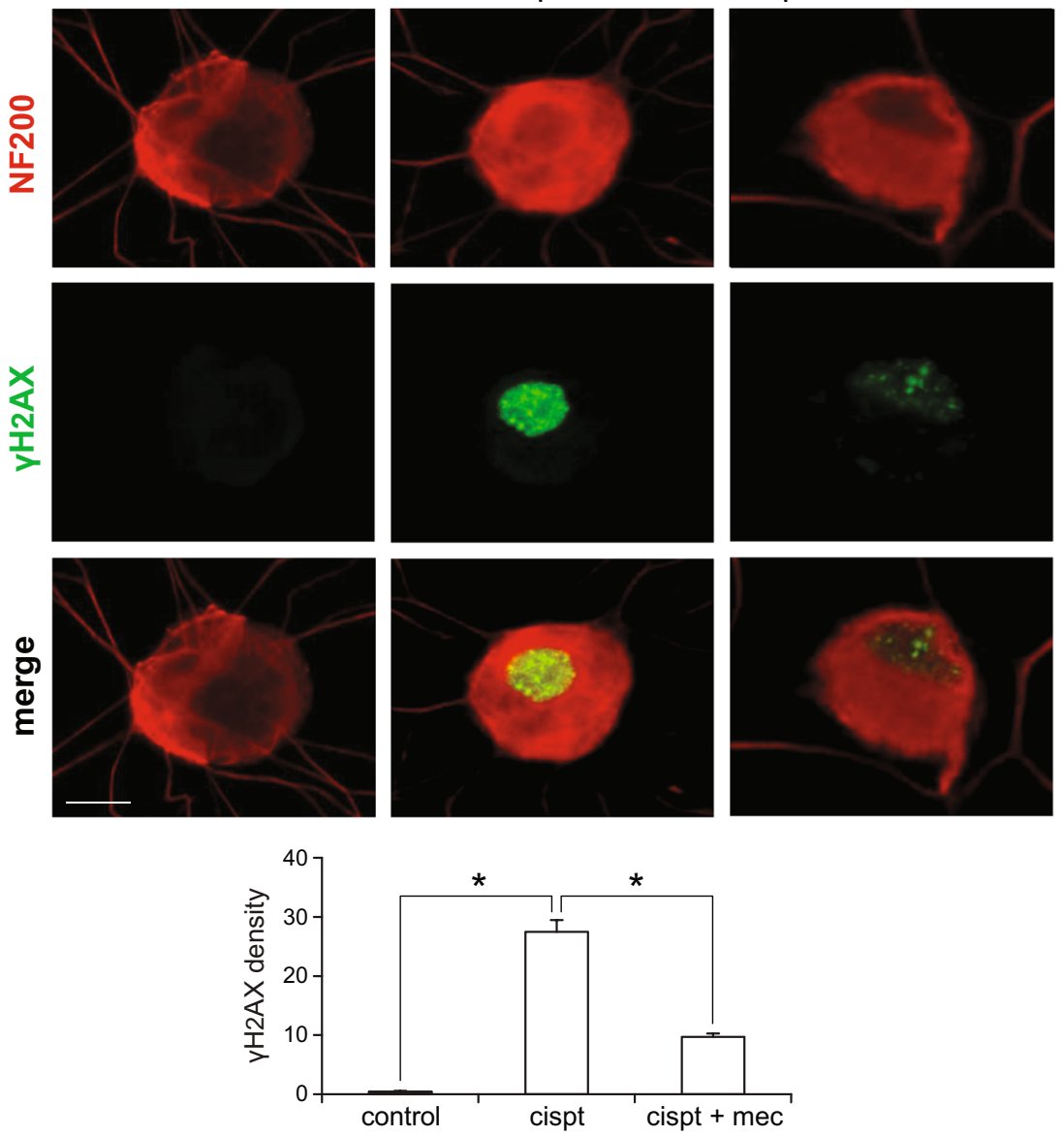